\title{
NMR Plasma Metabolomics Study of Patients Overcoming Acute Myocardial Infarction: in the First 12 h After Onset of Chest Pain With Statistical Discrimination Towards Metabolomic Biomarkers
}

\author{
Martin PETRAS ${ }^{1}$, Dagmar KALENSKA ${ }^{2}$, Matej SAMOS ${ }^{3}$, Tomas BOLEK ${ }^{3}$, Miroslava \\ SARLINOVA $^{1}$, Peter RACAY ${ }^{1,4}$, Erika HALASOVA ${ }^{1,5}$, Oliver STRBAK ${ }^{1}$, Jan STASKO ${ }^{6}$, \\ Ludovit MUSAK ${ }^{1}$, Michaela SKORVANOVA ${ }^{4}$, Eva BARANOVICOVA ${ }^{1}$ \\ ${ }^{1}$ Biomedical Center Martin, Comenius University in Bratislava, Jessenius Faculty of Medicine, \\ Martin, Slovak Republic, ${ }^{2}$ Department of Anatomy, Comenius University in Bratislava, Jessenius \\ Faculty of Medicine, Martin, Slovak Republic, ${ }^{3}$ Department of Internal Medicine I, Jessenius \\ Faculty of Medicine in Martin, Comenius University in Bratislava, Martin, Slovak Republic, \\ ${ }^{4}$ Department of Medical Biochemistry, Comenius University in Bratislava, Jessenius Faculty of \\ Medicine, Martin, Slovak Republic, ${ }^{5}$ Department of Medical Biology, Comenius University in \\ Bratislava, Jessenius Faculty of Medicine, Martin, Slovak Republic, ${ }^{6}$ Department of Hematology \\ and Blood Transfusion, National Centre of Thrombosis and Hemostasis, Jessenius Faculty of \\ Medicine in Martin, Comenius University in Bratislava, Slovak Republic
}

Received December 12, 2019

Accepted July 8, 2020

Epub Ahead of Print September 9, 2020

\section{Summary}

Acute myocardial infarction (AMI) is one of the leading causes of death among adults in older age. Understanding mechanisms how organism responds to ischemia is essential for the ischemic patient's prevention and treatment. Despite the great prevalence and incidence only a small number of studies utilize a metabolomic approach to describe AMI condition. Recent studies have shown the impact of metabolites on epigenetic changes, in these studies plasma metabolites were related to neurological outcome of the patients making metabolomic studies increasingly interesting. The aim of this study was to describe metabolomic response of an organism to ischemic stress through the changes in energetic metabolites and aminoacids in blood plasma in patients overcoming acute myocardial infarction. Blood plasma from patients in the first $12 \mathrm{~h}$ after onset of chest pain was collected and compared with volunteers without any history of ischemic diseases via NMR spectroscopy. Lowered plasma levels of pyruvate, alanine, glutamine and neurotransmitter precursors tyrosine and tryptophan were found. Further, we observed increased plasma levels of 3-hydroxybutyrate and acetoacetate in balance with decreased level of lipoproteins fraction, suggesting the ongoing ketonic state of an organism. Discriminatory analysis showed very promising performance where compounds: lipoproteins, alanine, pyruvate, glutamine, tryptophan and 3-hydroxybutyrate were of the highest discriminatory power with feasibility of successful statistical discrimination.

\section{Key words}

Myocardial infarction • Plasma • NMR metabolomics

\section{Corresponding author}

E. Baranovicova, Biomedical Center Martin, Comenius University in Bratislava, Jessenius Faculty of Medicine, Mala Hora 11161/4D, 036 01 Martin, Slovak Republic. E-mail: eva.baranovicova@uniba.sk

\section{Introduction}

Acute myocardial infarction (AMI), or heart attack, is one of the leading causes of death in the developed countries with lower incidence in women than men until midlife (Armeni and Lambrinoudaki 2017, Kittnar 2020). Healthy lifestyle should be encouraged already in children to avoid the development of AMI in future (Linhartová et al. 2019). Heart attack is most often caused by decrease or cessation of blood flow and the 
lack of oxygen in the coronary arteries, which results in impaired function of the part of the heart muscle or death (Alaour et al. 2018, Barberi and van den Hondel 2018). Atherosclerosis, dyslipidemia, hypertension, oxidation, inflammatory processes, as well as endothelial dysfunction and decreased glucose metabolism are considered to be the main risk factors for AMI (Trebatická et al. 2017).

Many studies confirm that the ischemic attack has its own metabolomic response not only in affected tissue but also in the circulation (Sidorov et al. 2019, Shah et al. 2012). Relatively much is known about blood glucose (Ishihara 2012) and lactate in patients overcoming AMI (Anderssen et al. 2013, Lazzeri et al. 2015). Interruption of blood supply to a certain region of the myocardium results in increased levels of enzymes in patient's blood such as: lactate dehydrogenase (LDH), creatine kinase (CK) and aspartate aminotransferase (AST) isoenzymes (Mythili and Malathi 2015) which are directly related to metabolites (Ussher et al. 2016). In the last years, the importance of metabolomics in cardiovascular diseases has increased and the metabolic profiles may serve as diagnostic and/or prognostic tools that have the potential to significantly alter the management of cardiovascular diseases (Ussher et al. 2016). It is relatively novel knowledge that some metabolites and metabolomic pathways have impact on epigenetics (Shimazu et al. 2013, Su et al. 2016, Ruan and Crawford 2018). Beside this, many clinical and experimental studies suggested the relation between plasma aminoacids levels and neurological outcome (Erdman et al. 2011, Coppola et al. 2013, Tournissac et al. 2018) making metabolomic studies increasingly attractive.

This study was designed to evaluate relative changes in plasma metabolites traceable by NMR spectroscopy which is a robust tool broadly used in untargeted metabolomics. Plasma from patients was sampled within $12 \mathrm{~h}$ after onset of chest pain and was compared with subjectively healthy volunteers without any history of ischemic diseases. The aim of this work was to describe metabolomic response of an organism to ischemic stress and explore the feasibility of statistical discrimination based on plasma metabolites.

\section{Materials and Methods}

\section{Samples}

Together 30 plasma samples from patients with hospital-confirmed acute myocardial infarction provided by Division of Invasive Cardiology, Department of Internal Medicine I of University Hospital Martin were used. Plasma was sampled in time of 2.5-12 h after onset of the chest pain. The patient group consisted of: 10 female, 20 male, aged: mean $=65 \pm 11$ years, median $=64 \pm 9$ years. Except one man, age 81 years, all patients survived the heart attack.

As controls, plasma samples from 30 subjectively healthy volunteers without any medically manifesting diseases and any history of acute coronary diseases were used, thereof 11 female, 19 male, aged: mean $=57 \pm 13$ years, median $=58 \pm 10$ years. For controls as well as for patients' selection, no additional criteria were used. Since in AMI it was not possible to plan the blood collection in advance, the blood sampling was carried on not insisting on fasting state for patients as for controls.

\section{Ethics}

This study was approved by the Ethics Committee of the Jessenius Faculty of Medicine in Martin (registered under IRB00005636 at Office for Human Research Protection, U.S. Department of Health and Human Services) under the code EK 1859/2016. Informed consent was obtained from all subjects of this study.

\section{Sample preparation}

Stock solution consisted of: $150 \mathrm{mM}$ phosphate buffer and $0.30 \mathrm{mM} \mathrm{TSP-d_{4 }} 3$-(trimethylsilyl)-propionic2,2,3,3- $\mathrm{d}_{4}$ acid sodium salt as a chemical shift reference in deuterated water. Blood was collected in EDTA coated tubes, centrifuged at $4{ }^{\circ} \mathrm{C}, 2000 \mathrm{rpm}$, for $20 \mathrm{~min}$. Plasma was deproteinated by adding $600 \mu \mathrm{l}$ of methanol to $300 \mu \mathrm{l}$ of plasma. The mixture was vortexed for a few seconds and stored at $-20^{\circ} \mathrm{C}$ for $20 \mathrm{~min}$. Then, the mixture was centrifuged for $30 \mathrm{~min}$ at $14000 \mathrm{rpm}$. Finally, $700 \mu \mathrm{l}$ of supernatant were dried out and subsequently carefully mixed with $100 \mu \mathrm{l}$ of stock solution and $500 \mu \mathrm{l}$ of deuterated water. $550 \mu \mathrm{l}$ of final mixture were transferred into $5 \mathrm{~mm}$ NMR tube.

\section{NMR data acquisition}

NMR data were acquired on $600 \mathrm{MHz}$ NMR spectrometer Avance III from Bruker equipped with TCI (triple resonance) cryoprobe. Initial settings were done on an independent sample and adopted for measurements. Samples were stored in Sample Jet at approx. $6{ }^{\circ} \mathrm{C}$ and randomly ordered for acquisition. Measurements were carried on at $310 \mathrm{~K}$. An exponential noise filter was used to introduce $0.3 \mathrm{~Hz}$ line broadening before Fourier transform. We used standard Bruker 
profiling protocols that we modified as follows: profiling 1D NOESY with presaturation (noesygppr1d): FID size $64 \mathrm{k}$, dummy scans 4 , number of scans 128 , spectral width 20.4750 ppm; COSY with presaturation (cosygpprqf): FID size 4k, dummy scans 8 , number of scans 1 , spectral width $\quad 16.0125 \mathrm{ppm}$; homonuclear $J$-resolved (jresgpprqf): FID size 8k, dummy scans 16, number of scans 4; profiling CPMG with presaturation (cpmgpr1d, L4=126, d20=3ms): FID size $64 \mathrm{k}$, dummy scans 4, number of scans 128, spectral width 20.0156 ppm. All experiments were conducted with a relaxation delay of $4 \mathrm{~s}$; all data were once zero filled.

\section{Data analysis}

TSP- $\mathrm{d}_{4}$ signal was assigned a chemical shift of $0.000 \mathrm{ppm}$. All spectra were binned to bins of the size of $0.001 \mathrm{ppm}$, starting from $0.500 \mathrm{ppm}$ to $9.000 \mathrm{ppm}$, with excluded water region 4.6-4.9 ppm. Spectra were solved with the help of human metabolome database (www.hmdb.ca), Chenomx software and by searching in metabolomics literature. For all compounds the multiplicity of peaks was confirmed in J-resolved spectra and homonuclear cross peaks were confirmed in cosy spectra.

Metabolites showing weak intensive peaks or peaks overlap were excluded from the evaluation. After the metabolites were identified (Table 1), we chose the spectra subregions with only single metabolite assigned. In 0.001 ppm binned spectra we summed integrals of selected signals. These data representing relative concentration of metabolites in plasma were used for statistical analysis. No normalization method was applied on NMR data. After normality test by Shapiro-Wilk and Kolmorogov test (OriginPro 2019) statistical analysis was carried on using Mann- $U$-Whitney test (Matlab R2015a). Principal component analysis (PCA), partial least squares discriminant analysis (PLS-DA) and receiver operating characteristic (ROC) curves derived from random forest (RF) algorithm were performed by using Metaboanalyst 4.0 (Chong et al. 2019) and Matlab R2015a.

Table 1. Plasma metabolites: ${ }^{1} \mathrm{H}$ NMR chemical shifts used for identification, in bold chemical shifts used for quantification (all or the part of, s-singlet, d-doublet, t-triplet, q-quarte, m-multiplet).

\begin{tabular}{|c|c|}
\hline Metabolite & Peaks assigned \\
\hline Threonine & $1.33 \mathrm{~d}, 3.60 \mathrm{~d}, 4.26 \mathrm{dq}$ \\
\hline Lactate & $1.34 \mathrm{~d}, \mathbf{4 . 1 5 q}$ \\
\hline Formate & $8.46 \mathrm{~s}$ \\
\hline Alanine & $\mathbf{1 . 4 8 d}, 3.81 \mathrm{q}$ \\
\hline Valine & $0.99 d, 1.05 d, 2.28 m, 3.62 d$ \\
\hline Glucose & $\begin{array}{c}3.25 \mathrm{dd}, 3.40 \mathrm{t}, 3.41 \mathrm{dd}, 3.47 \mathrm{~m}, 3.49 \mathrm{~m}, 3.53 \mathrm{dd}, 3.71 \mathrm{t}, 3.72 \mathrm{~m}, 3.76 \mathrm{~m}, 3.83 \mathrm{~m}, 3.84 \mathrm{~m}, \mathbf{3 . 9 0 d d} \text {, } \\
4.63 \mathrm{~d}, 5.23 \mathrm{~d}\end{array}$ \\
\hline Leucine & $0.96 \mathrm{~d}, 0.97 \mathrm{~d}, 1.72 \mathrm{~m}$ \\
\hline Isoleucine & $0.94 \mathrm{t}, 1.01 \mathrm{~d}, 3.67 \mathrm{~d}$ \\
\hline Acetoacetate & $2.28 \mathrm{~s}$ \\
\hline Acetate & $1.91 \mathrm{~s}$ \\
\hline Pyruvate & $2.37 \mathrm{~s}$ \\
\hline Citrate & $2.55 d, 2.66 d$ \\
\hline 2-oxoisocaproate & $0.95 \mathrm{~d}, 2.1 \mathrm{~m}, \mathbf{2 . 6 1 d}$ \\
\hline Phenylalanine & 7.33d, 7.38t, $7.42 \mathrm{t}$ \\
\hline Tryptophan & $7.19 \mathrm{t}, 7.27 \mathrm{t}, 7.31 \mathrm{~s}, \mathbf{7 . 5 5 d}, \mathbf{7 . 7 4 d}$ \\
\hline Tyrosine & $6.90 d, 7.15 d$ \\
\hline Creatine & $3.03 \mathrm{~s}, \mathbf{3 . 9 3 \mathrm { s }}$ \\
\hline Creatinine & $3.04 \mathrm{~s}, \mathbf{4 . 0 5 s}$ \\
\hline Glutamine & $2.11 \mathrm{~m}, 2.14 \mathrm{~m}, 2.44 \mathrm{~m}, 2.47 \mathrm{~m}$ \\
\hline 3-hydroxybutyrate & $1.20 \mathrm{~d}, 2.31 \mathrm{dd}, 2.39 \mathrm{dd}, 4.15 \mathrm{~m}$ \\
\hline Lipoproteins & 0.8-0.87m, 1.19-1.33m (Liu et al. 2002) \\
\hline
\end{tabular}




\section{Results}

Together 20 plasma metabolites from 21 identified (except threonine, Table 1) were quantified. Statistically significant ( $\mathrm{p}<0.05$, Mann- $U$-Whitney test) changes in plasma metabolite levels in patients' group against controls are summarized in Table 2. Other metabolites were without significant changes. Lipoproteins fraction contained mainly VLDL, LDL, HDL and IDL as described in the work by Liu et al. (2002).

Table 2. Relative changes in plasma metabolites in patients after AMI against subjectively healthy controls, $p$-value derived from Mann- $U$-Whitney test, \% change derived from median.

\begin{tabular}{lcc}
\hline Metabolite & p-value & $\begin{array}{c}\text { \% change in } \\
\text { patients } \\
\text { against } \\
\text { controls }\end{array}$ \\
\hline Glucose & $\mathrm{p}<0.005$ & 26 \\
Pyruvate & $\mathrm{p}<0.0005$ & -34 \\
Alanine & $\mathrm{p}<0.0005$ & -17 \\
Tryptophan & $\mathrm{p}<0.000005$ & -28 \\
Tyrosine & $\mathrm{p}<0.05$ & -11 \\
Glutamine & $\mathrm{p}<0.005$ & -18 \\
3-hydroxybutyrate & $\mathrm{p}<0.00005$ & 57 \\
Acetoacetate & $\mathrm{p}<0.0005$ & 40 \\
Lipoproteins & $\mathrm{p}<0.000005$ & -45 \\
\hline
\end{tabular}

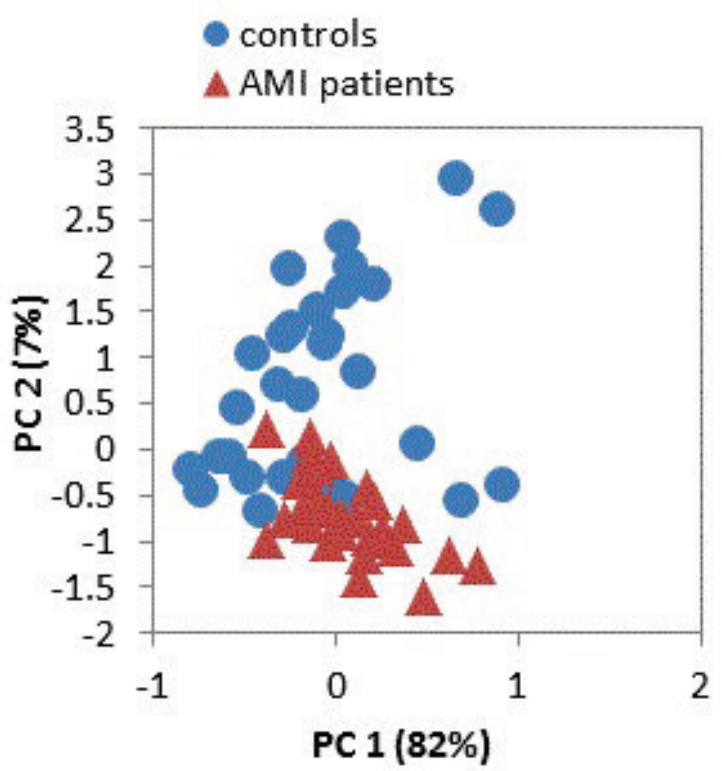

\section{PCA, PLS-DA analysis}

Firstly, the results were visualized by PCA and PLS-DA methods (Fig. 1). PCA is a tool for exploratory data analysis and, in addition to other uses, provides a $2 \mathrm{D}$ plot of the multivariate data. Unlike PCA, PLS-DA includes also a discrimination algorithm. We used relative concentrations of plasma metabolites determined by NMR spectroscopy as an input for the PCA and PLS-DA algorithm. Both analyzes suggested that good discrimination between patients and controls is attainable (Fig. 1). In order to show the reliability of PLS-DA, the PLS-DA results are presented along with the results of permutation test and leave-one-out cross-validation (LOOCV). In permutation test, we permuted the y-values 1000 times and showed the resulting Rsquare (value calculated based on the difference between the real outcome and the outcome predicted) distribution together with Rsquare value determined on true labeled samples (Fig. 2). In the each iteration of LOOCV, one sample was left out and the multivariate model was constructed by the rest of the samples. Then the predicted value of omitted sample was calculated based on model created. The entire procedure was repeated until each case had been omitted once. Finally, we calculated Rsquare, Qsquare and accuracy that were (in the mentioned order): $0.72,0.306$ and -0.11 for 5 components and $0.74,0.52$ and -3.98 for 8 components. The results from PCA and PLS-DA analysis based on spectral NMR bins of $0.001 \mathrm{ppm}$ are shown in the Supplementary material.

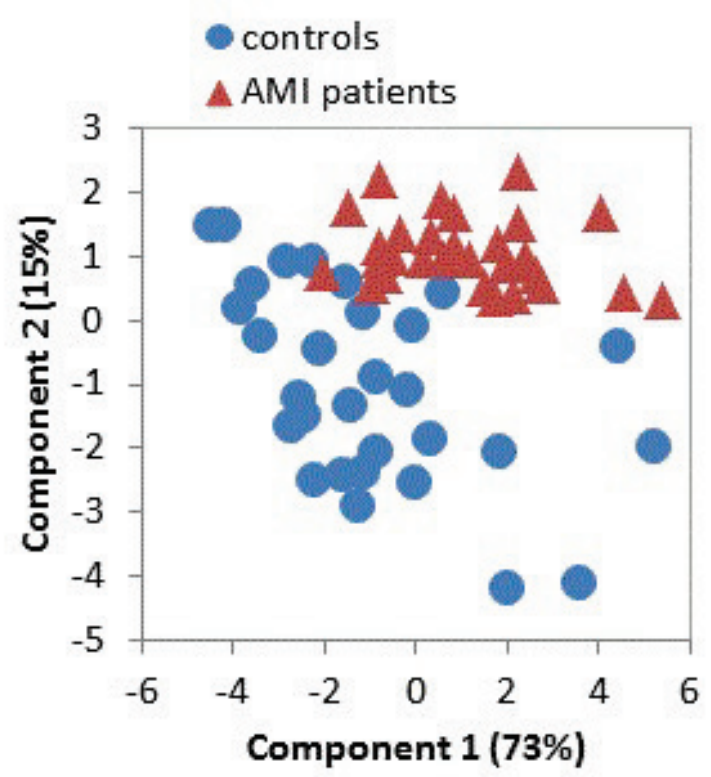

Fig. 1. PCA (left) and PLS-DA (right) analysis of plasma metabolites in patients after ischemic attack in comparison to controls. 


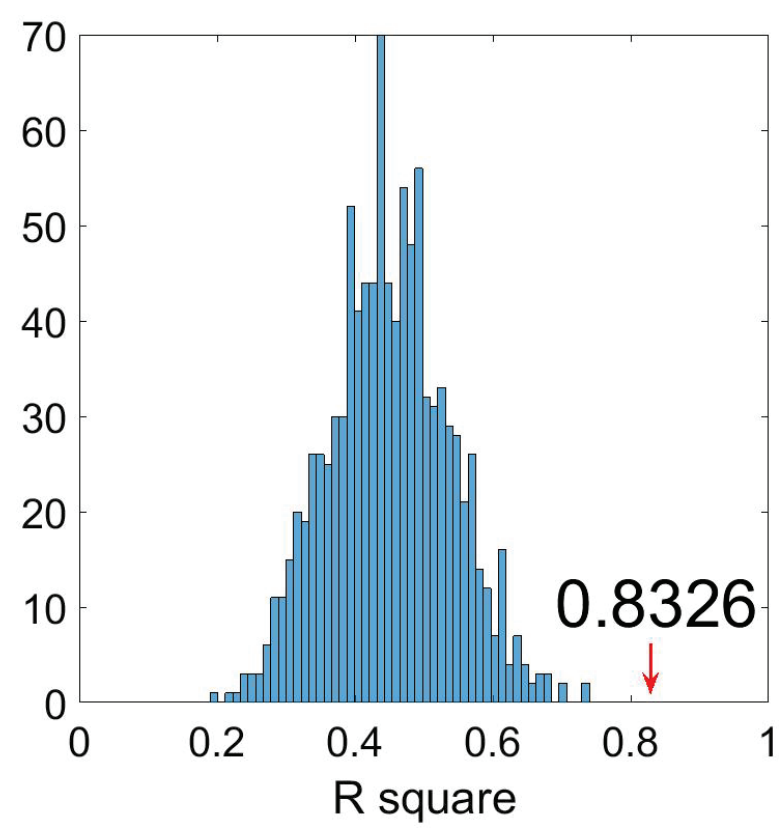

Fig. 2. PLSDA permutation test: expressed by histogram of Rsquare values with marked Rsquare value after PLSDA on truly labeled samples.

\section{Random Forest classification}

In the same way as in PCA and PLS-DA, the input variables for $\mathrm{RF}$ were the relative plasma concentration of metabolites. After RF run, ROC curve was created. ROC curve analysis is the standard method for describing and assessing the performance of diagnostic - discrimination tests. It is produced by plotting the true positive rate against the false positive rate at various threshold settings. An important parameter, area under curve (AUC) represents ranking quality. The AUC of a ranking is 1 (the maximum of AUC value) when all samples are truly assigned into the groups. An AUC of 0.5 is equivalent to randomly classifying subjects as either positive or negative (the classifier is of no practical utility). When evaluated AMI patients against controls, an excellent classification with AUC of 0.97 for $n=2$ features (alanine and lipoproteins) and AUC of 0.985 for $\mathrm{n}=5$ features (alanine, lipoproteins, pyruvate, tryptophan and glutamine) was obtained. By including further metabolites $n=10$, we obtained AUC of 0.989 and with $n=20$, AUC of 0.992 was achieved.

\section{Discussion}

\section{Biochemical aspects related to heart attack}

Significantly increased plasma glucose level found in AMI patients was expected as acute hyperglycemia is a common feature during the early phase after acute myocardial infarction regardless of diabetes status (Ishihara 2012). As a result of tissue hypoxia and accelerated anaerobic glycolysis, lactate plasma level increases. Elevated plasma lactate level in AMI patients can vary depending on extent of injury (Andersen et al. 2013) and can serve as a predictor of early mortality (Lazzeri et al. 2015). During shock, lactate is the most important fuel for the heart and rather than its absolute value, the lactate clearance has been reported as clinically more reliable (Abramson et al. 1993, Zhang and Xu 2014). It has been demonstrated in previous studies that after ischemic attack, the amount of lactate gradually decreases during reperfusion time, both in the brain parenchyma (Liu and Li 2016) as well as in blood (Rehncrona et al. 1981, Kliegel et al. 2004). In our study, we did not observe significantly increased lactate level in blood plasma in cardiac patients (Fig. 3), as it can be expected in early time after onset of the chest pain. As the lactate is rapidly consumed in stress condition by heart, brain and other tissues, the time of blood collection plays an important role. Normalization of lactate level after AMI was observed within $24 \mathrm{~h}$ (Kliegel et al. 2004), and also in patients who underwent therapeutic hypothermia within $48 \mathrm{~h}$ respectively (Lee et al. 2013). The fact that 29 from 30 patients examinated in our study survived the AMI indicates better general outcome in studied group what is related to faster lactate clearance. It is to note that there were no special criteria in selecting the control group regarding diabetes or other metabolomic disorders which may cause e.g. lactic acidosis in uninjured group and also influence the statistical result.

Lactate metabolism is closely interconnected with pyruvate and alanine where the mutual conversion of these metabolites occurs in Cori and Cahill cycles. Unlike lactate, AMI patients showed significantly decreased plasma levels of aerobic glycolysis intermediate pyruvate and amino acid alanine (Table 2, Fig. 3). In the liver, the carbon skeleton of alanine is through pyruvate reconverted to glucose and released into the bloodstream. Circulating glucose is available for uptake by muscle and resynthesis of alanine in pyruvatealanine cycle. The decreased plasma levels of alanine and pyruvate suggest the modifications in alanine- and pyruvate-related metabolism induced by AMI injury.

At the time of altered glucose utilization, alternative substrates such as ketone bodies could support metabolic requirements. Ketone bodies can provide more than two thirds of the brain energy demands more 
efficiently than glucose (Puchalska and Crawford 2017). Very recent study showed that failing heart utilizes 3-hydroxybutyrate as a metabolic stress defense (Horton et al. 2019). In our study, we observed significantly increased plasma levels of ketone 3-hydroxybutyrate and its redox partner acetoacetate. The increase in plasmatic ketone bodies in blood after brain ischemic injury has been already described in rodents (Baranovicova et al. 2018a, Baranovicova et al. 2018b). It is to note, that the levels of glycolytic intermediates and ketone bodies in blood plasma are strongly dependent on diet and time elapsed from last food intake. 3-hydroxybutyrate level in starving subjects starts to increase prominently after 4-8 h (Cahill 2006). After the onset of chest pain, no food intake by patients can be assumed, although in this study, no exact data were collected to confirm it. With respect to these facts, we cannot recognize the define origin of increased plasma ketone bodies and this may result from combination of both, starvation and ischemic attack. Parallel to increased plasmatic ketone bodies, a significant decrease in lipoprotein fraction containing LDL, HDL and VLDL was observed. This fraction besides others contains the main substrates for ketone bodies production, such as triacylglycerols (Liu et al. 2002). Detailed profile of plasma lipids in AMI patients was already described showing decrease in LDL and HDL after AMI (Kumar et al. 2019).

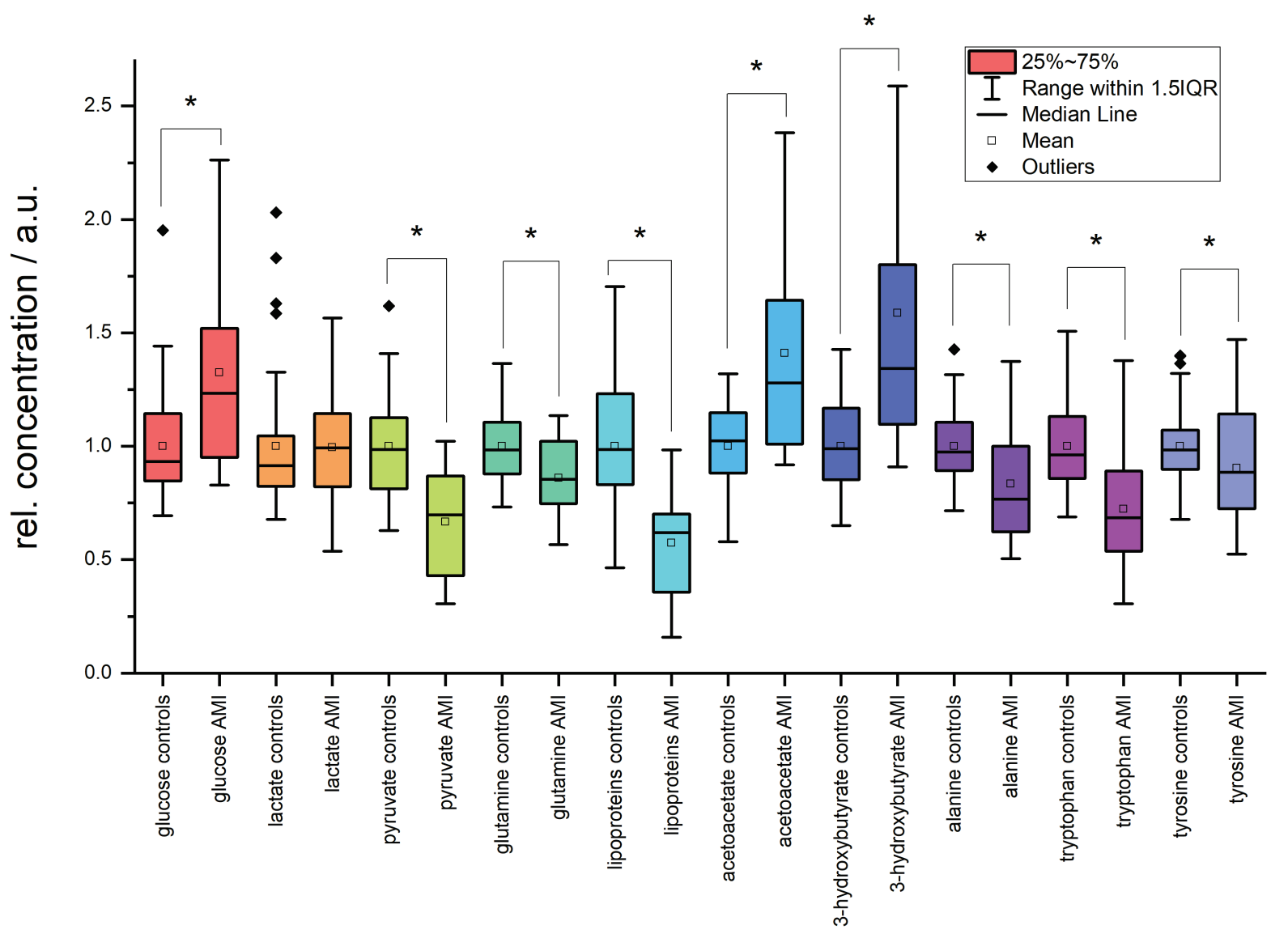

Fig. 3. Relative plasma concentration of selected metabolites determined via NMR.

Ketone bodies besides serving as fuel in metabolic pathways coordinate cellular function via epigenomic regulation (Ruan and Crawford 2018). There is evidence that increased level of ketone bodies, above all of 3-hydroxybutyrate, may influence epigenetic histone acetylation (Shimazu et al. 2013, Su et al. 2016). The ketonic state with increased plasma ketone bodies 3-hydroxybutyrate and acetoacetate is interfering with the level of NAD and in further may influence eventual histone acetylation (Su et al. 2016). Histone deacetylase inhibitors provide beneficial cardiac and vascular protective effects in rats with pressure overload cardiac hypertrophy (Jung et al. 2019). As next, methylation status is sensitive to oxygen and TCA-related metabolism (Su et al. 2016). Lai et al. (2014) showed that TCA cycle intermediates in heart failure patients are reduced (Aubert 
et al. 2016). It is to consider that the metabolic enzyme expression has the potential to impact DNA methylation and histone acetylation in mammals ( $\mathrm{Su}$ et al. 2016), what makes detailed metabolomic and enzymatic studies all the more interesting and useful.

Glutamine is conditionally essential in humans and in some instances of stress the demand of body for glutamine increases. It serves as fuel for lymphocytes and macrophages (Parry-Billings et al. 1992), it is involved in modulating immune cells function and protecting them from apoptosis (Chang et al. 2002). Glutamine also plays a crucial role in the production of cytokines (Shah et al. 2020). During catabolic/hypercatabolic situations glutamine can become essential for metabolic function but its availability may be compromised due to the impairment of homeostasis in the inter-tissue metabolism of amino acids. Reduced plasma level of glutamine was observed in various emergency conditions including surgical interventions (Parry-Billings et al. 1992). In cardiac patients, intracellular myocardial glutamine concentrations were reduced (Suleiman et al. 1997). Interestingly, experimental and clinical studies have demonstrated the cardio protective effect of glutamine. For example, the beneficial effect of glutamine on ischemic rat heart was shown by Khogali et al. (2002). Consistently with current knowledge, we observed significantly lowered glutamine plasma levels in patients overcoming AMI when compared with controls.

Tryptophan is an essential amino acid and besides participating in the biosynthesis of proteins it serves as a precursor to kynurenine metabolites, neurotransmitter serotonin and others. The role of tryptophan metabolism in cardiovascular diseases was summarized by Lenhert et al. (2014). It is i.e. involved in endothelium derived blood pressure control and microvascular reactivity in stroke (Mangge et al. 2014). Tyrosine is conditionally essential amino acid for patients with chronic renal failure having various relations to vascular system. In our study, both tyrosine and tryptophan plasma levels were observed to be decreased in AMI patients against controls, similarly as it was in stroke patients in study by Ormstad et al. (2013), suggesting increased rate of their metabolic conversion. These findings indicated that the proinflammatory response may be responsible for a reduced capacity for the biosynthesis of brain catecholamines and mediates neurotoxic effects. Results of many studies support this concept, e.g. patients after AMI suffered cognitive and somatic depressive symptoms with depression recognition (Smolderen et al. 2009), they have also a higher risk of anxiety and depressive disorders (Feng et al. 2016), cognitive impairment (Gharacholou et al. 2011) and other impairments.

As methodological note: some metabolites such as lactate or tryptophan bind to serum albumin (Cunningham et al. 1975) what influences the concentration of 'free' metabolites in blood plasma. During deproteinization procedure proteins are denaturized and non-specifically bound substances are likely to be released. We did not run additional experiments to examine this process in detail, however we would not expect much impact on the results.

\section{Biomarkers discovery}

There are two main approaches in data evaluation and interpretation in the metabolomics. The first of them is focused on gaining the improved biological understanding through analyzing metabolite profiles. Here, p-values from hypothetical statistical testing are used as essential statistical tools. While lists of compounds found to be significantly changed are sometimes referred as 'putative biomarkers', they are not really useful as clinical biomarkers which require different analysis, evaluation and validation (Xia et al. 2013). The second fundamental metabolomic approach is oriented towards biomarkers that are not intended to explain biology but they are rather designed to discriminate with an optimal sensitivity/specificity (Xia et al. 2013). Whereas PCA serves to visualise data in 2D format, supervised PLS-DA includes also a discrimination algorithm. Both, PCA as well as PLS-DA suggested the good potential of the system to obtain sufficient discrimination (Fig. 1ab). However, PLS-DA models have a very strong propensity to overfit the training data mainly under high dimensionalities and small sample conditions (Rodríguez-Pérez et al. 2018). We run additional tests to confirm the reliability of PLS-DA results. As can be seen from Figure 2, the permutation test shows a relatively good reliability of PLS-DA analysis to discriminate between cases and controls with Rsquare $=0.8326$. In contrast, the Qsquare values from LOOCV cross validation suggest overfitted PLS-DA model.

To estimate the more realistic discriminatory power of the system, we decided to employ random forest discriminatory analysis. Cross validated RF algorithm picks up two-third data for training and rest for testing for regression and almost $70 \%$ data for training and rest for 


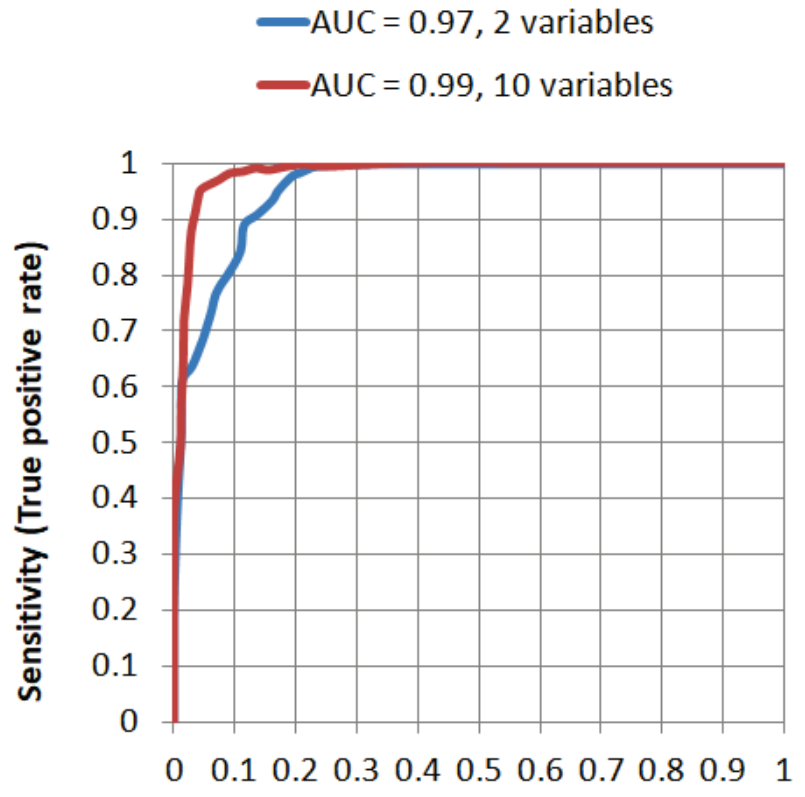

1-Specificity (False positive rate)

Fig. 4. ROC curve based on Random Forest classification for plasma metabolites determined by NMR is showing very good performance with AUC very close to 1 for system AMI patients controls.

testing during classification in order to overcome the training and testing on the same data. Although this approach does not substitute the clinical validation, it may lead to encouraging results in exploratory studies. The further advantage of RF algorithm is identifying the most important features that are responsible for success of discrimination. Random Forest in our study performed very well with AUC of 0.97 for only two variables: lipoproteins and alanine. With increasing number of variables, the AUC was getting closer to 1 (Fig. 4). It is to note, that the obtained performance could be achieved by various combination of variables that permuted in importance order. For example, if alanine was excluded from the variables, RF performed also very well with AUC very close to 1 for two metabolites, lipoproteins and tryptophan. The discriminatory power of this system was not dependent exclusively on one particular metabolite but offered various combinations to achieve very good results. As examples, very good discrimination was achieved by using relative concentration of plasma metabolites: lipoproteins and alanine $(\mathrm{AUC}=0.97)$, lipoproteins and pyruvate ( $\mathrm{AUC}=0.97)$, alanine and pyruvate $(\mathrm{AUC}=0.92$ ), lipoproteins and tryptophan $(\mathrm{AUC}=0.96)$, lipoproteins and glutamine ( $\mathrm{AUC}=0.97$ ). Having run $\mathrm{RF}$ with various combinations of variables as an input, we observed that following metabolites combined together gave the best discriminatory performance and behaved in our study as potential plasma biomarkers of AMI: lipoproteins, alanine, pyruvate, glutamine, tryptophan and 3-hydroxybutyrate. In addition to metabolomics, proteomics approach seems to be also a suitable method to identify reliable specific novel biomarkers in heart failure. Rehulkova et al. (2016) found a number of proteins with unique changes in plasma levels. More studies are required for complete the understanding and clarifying the pathophysiology of serious complications (Lacko et al. 2018) of acute cardiogenic shock from which the patient would ultimately benefit.

\section{Conclusions}

In patients overcoming AMI, besides expected hyperglycemia, the decrease in plasma level of pyruvate, alanine, glutamine, tyrosine and tryptophan was found. The elevated plasma levels of ketone bodies 3-hydroxybutyrate and acetoacetate, parallel to decrease in plasma lipoprotein fraction point out on the ongoing ketogenic state. PCA and PLS-DA analyzes separated favorably but not ideally patients from controls. By employing cross-validated Random Forest algorithm, we obtained almost ideal discrimination of patients from controls where following metabolites combined together gave the best discriminatory performance: lipoproteins, alanine, pyruvate, glutamine, tryptophan and 3-hydroxybutyrate. Based on the obtained results, we would like to emphasize the very promising possibility to discriminate between AMI patients and controls on the basis of principal plasma metabolites.

\section{Conflict of Interest}

There is no conflict of interest.

\section{Acknowledgements}

This work was supported by Scientific Grant Agency of the Slovak Republic grant No. VEGA 1/0277/18 and No. VEGA 1/0090/20, project "Competence Center for Research and Development in Diagnosis and Therapy of Oncological Diseases" code 26220220153 co-financed from EU sources and European Regional Development Fund, the Slovak Research and Development Agency under contract no. APVV-0224-12 and APVV-16-0020, Ministry of Health Slovakia under the grant Nr. 2018/11UKMT-7. 


\section{References}

ABRAMSON D, SCALEA TM, HITCHCOCK R, TROOSKIN SZ, HENRY SM, GREENSPAN J: Lactate clearance and survival following injury. J Trauma 35: 584-588, discussion 588-589, 1993. https://doi.org/10.1097/00005373-199310000-00014

ALAOUR B, LIEW F, KAIER TE: Cardiac troponin - diagnostic problems and impact on cardiovascular disease. Ann Med 50: 655-665, 2018. https://doi.org/10.1080/07853890.2018.1530450

ANDERSEN LW, MACKENHAUER J, ROBERTS JC, BERG KM, COCCHI MN, DONNINO MW: Etiology and therapeutic approach to elevated lactate levels. Mayo Clin Proc 88: 1127-1140, 2013. https://doi.org/10.1016/j.mayocp.2013.06.012

ARMENI E, LAMBRINOUDAKI I: Androgens and cardiovascular disease in women and men. Maturitas 104: 54-72, 2017. https://doi.org/10.1016/j.maturitas.2017.07.010

AUBERT G, MARTIN OJ, HORTON JL, LAI L, VEGA RB, LEONE TC, KOVES T, GARDELL SJ, KRÜGER M, HOPPEL CL, LEWANDOWSKI ED, CRAWFORD PA, MUOIO DM, KELLY DP: The failing heart relies on ketone bodies as a fuel. Circulation 133: 698-705, 2016. https://doi.org/10.1161/circulationaha.115.017355

BARANOVICOVA E, GRENDAR M, KALENSKA D, TOMASCOVA A, CIERNY D, LEHOTSKY J: NMR metabolomic study of blood plasma in ischemic and ischemically preconditioned rats: an increased level of ketone bodies and decreased content of glycolytic products $24 \mathrm{~h}$ after global cerebral ischemia. J Physiol Biochem 74: 417-429, 2018b. https://doi.org/10.1007/s13105-018-0632-2

BARANOVICOVA E, KALENSKA D, TOMASCOVA A, LEHOTSKY J: Metabolomic study of altered energy metabolism during global forebrain ischemia and ischemic precoditioning in blood plasma in homocysteine treated rats. J Physiol Pharmacol 69: 901-909, 2018a. https://doi.org/10.1007/s13105-018-0632-2

BARBERI C, VAN DEN HONDEL KE: The use of cardiac troponin T (cTnT) in the postmortem diagnosis of acute myocardial infarction and sudden cardiac death: A systematic review. Forensic Sci Int 292: 27-38, 2018. https://doi.org/10.1016/j.forsciint.2018.09.002

CAHILL GF JR: Fuel metabolism in starvation. Annu Rev Nutr 26: 1-22, 2006. https://doi.org/10.1146/annurev.nutr.26.061505.111258

CHANG WK, YANG KD, CHUANG H, JAN JT, SHAIO MF: Glutamine protects activated human T cells from apoptosis by up-regulating glutathione and Bcl-2 levels. Clin Immunol 104: 151-160, 2002. https://doi.org/10.1006/clim.2002.5257

CHONG J, WISHART DS, XIA J: Using MetaboAnalyst 4.0 for comprehensive and integrative metabolomics data analysis. Curr Protoc Bioinformatics 68: e86, 2019. https://doi.org/10.1002/cpbi.86

COPPOLA A, WENNER BR, ILKAYEVA O, STEVENS RD, MAGGIONI M, SLOTKIN TA, LEVIN ED, NEWGARD CB: Branched-chain amino acids alter neurobehavioral function in rats. Am J Physiol Endocrinol Metab 304: E405-E413, 2013. https://doi.org/10.1152/ajpendo.00373.2012

CUNNINGHAM VJ, HAY L, STONER HB: The binding of L-tryptophan to serum albumins in the presence of nonesterified fatty acids. Biochem J 146: 653-658, 1975. https://doi.org/10.1042/bj1460653

ERDMAN J, ORIA M, PILLSBURY L: Nutrition and traumatic brain injury: Improving acute and subacute health outcomes in military personnel. Institute of Medicine (US) Committee on Nutrition, Trauma, and the Brain, Washington (DC): National Academies Press (US): 2011. https://doi.org/10.17226/13121

FENG HP, CHIEN WC, CHENG WT, CHUNG CH, CHENG SM, TZENG WC: Risk of anxiety and depressive disorders in patients with myocardial infarction: A nationwide population-based cohort study. Medicine (Baltimore) 95: e4464, 2016. https://doi.org/10.1097/md.0000000000004464

GHARACHOLOU SM, REID KJ, ARNOLD SV, SPERTUS J, RICH MW, PELLIKKA PA, SINGH M, HOLSINGER T, KRUMHOLZ HM, PETERSON ED, ALEXANDER KP: Cognitive impairment and outcomes in older adult survivors of acute myocardial infarction: findings from the translational research investigating underlying disparities in acute myocardial infarction patients' health status registry. Am Heart J 162: 860-869.e1, 2011. https://doi.org/10.1016/j.ahj.2011.08.005 
HORTON JL, DAVIDSON MT, KURISHIMA C, VEGA RB, POWERS JC, MATSUURA TR, PETUCCI C, LEWANDOWSKI ED, CRAWFORD PA, MUOIO DM, RECCHIA FA, KELLY DP: The failing heart utilizes 3-hydroxybutyrate as a metabolic stress defense. JCI Insight 4: pii: 124079, 2019. https://doi.org/10.1172/jci.insight.124079

ISHIHARA M: Acute hyperglycemia in patients with acute myocardial infarction. Circ J 76: 563-571, 2012. https://doi.org/10.1253/circj.cj-11-1376

JUNG H, LEE E, KIM I, SONG JH, KIM GJ: Histone deacetylase inhibition has cardiac and vascular protective effects in rats with pressure overload cardiac hypertrophy. Physiol Res 68: 727-737, 2019. https://doi.org/10.33549/physiolres.934110

KHOGALI SE, PRINGLE SD, WERYK BV, RENNIE MJ: Is glutamine beneficial in ischemic heart disease? Nutrition 18: 123-126, 2002. https://doi.org/10.1016/s0899-9007(01)00768-7

KITTNAR O: Selected sex related differences in pathophysiology of cardiovascular system. Physiol Res 69: 21-31, 2020. https://doi.org/10.33549/physiolres. 934068

KLIEGEL A, LOSERT H, STERZ F, HOLZER M, ZEINER A, HAVEL C, LAGGNER AN: Serial lactate determinations for prediction of outcome after cardiac arrest. Medicine (Baltimore) 83: 274-279, 2004. https://doi.org/10.1097/01.md.0000141098.46118.4c

KUMAR N, KUMAR S, KUMAR A, SHAKOOR T, RIZWAN A: Lipid profile of patients with acute myocardial infarction (AMI). Cureus 11: e4265, 2019. https://doi.org/10.7759/cureus.4265

LACKO S, MLČEK M, HÁLA P, POPKOVÁ M, JANÁK D, HRACHOVINA M, KUDLIČKA J, HRACHOVINA V, OŠŤÁDAL P, KITTNAR O: Severe acute heart failure - experimental model with very low mortality. Physiol Res 67: 555-562, 2018. https://doi.org/10.33549/physiolres.933774

LAI L, LEONE TC, KELLER MP, MARTIN OJ, BROMAN AT, NIGRO J, KAPOOR K, KOVES TR, STEVENS R, ILKAYEVA OR, VEGA RB, ATTIE AD, MUOIO DM, KELLY DP: Energy metabolic reprogramming in the hypertrophied and early stage failing heart: a multisystems approach. Circ Heart Fail 7: 1022-1031, 2014. https://doi.org/10.1161/circheartfailure.114.001469

LAZZERI C, VALENTE S, CHIOSTRI M, GENSINI GF: Clinical significance of lactate in acute cardiac patients. World J Cardiol 26: 483-489, 2015. https://doi.org/10.4330/wjc.v7.i8.483

LEE TR, KANG MJ, CHA WC, SHIN TG, SIM MS, JO IJ, SONG KJ, JEONG YK, CHO JH: Better lactate clearance associated with good neurologic outcome in survivors who treated with therapeutic hypothermia after out-ofhospital cardiac arrest. Crit Care 17: R260, 2013. https://doi.org/10.1186/cc13090

LEHNERT H, BEYER J, HELLHAMMER DH: Effects of L-tyrosine and L-tryptophan on the cardiovascular and endocrine system in humans. In: Amino Acids. LUBEC G, ROSENTHAL GA (eds), Springer, Dordrecht, 1990, pp 618-625. https://doi.org/10.1007/978-94-011-2262-7_72

LINHARTOVÁ K, BUDINSKAYA K, SVAČINOVÁ J, SVÍZELA V, PROKEŠ M, PROKEŠOVÁ-KOSOVÁ N, NOVÁK J, NOVÁKOVÁ Z: Status of nutrition and cardiovascular system in children from the south Moravian region of the Czech Republic: a pilot study. Physiol Res 68 (Suppl 3): S243-S251, 2019. https://doi.org/10.33549/physiolres.934355

LIU M, TANG H, NICHOLSON JK, LINDON JC: Use of 1H NMR-determined diffusion coefficients to characterize lipoprotein fractions in human blood plasma. Magn Reson Chem 40: S83-S88, 2002. https://doi.org/10.1002/mrc.1121

LIU Z, LI Y: Cortical cerebral blood flow, oxygen extraction fraction, and metabolic rate in patients with middle cerebral artery stenosis or acute stroke. AJNR Am J Neuroradiol 37: 607-614, 2016. https://doi.org/10.3174/ajnr.a4624

MANGGE H, STELZER I, REININGHAUS EZ, WEGHUBER D, POSTOLACHE TT, FUCHS D: Disturbed tryptophan metabolism in cardiovascular disease. Curr Med Chem 21: 1931-1937, 2014. https://doi.org/10.2174/0929867321666140304105526

MYTHILI S, MALATHI N: Diagnostic markers of acute myocardial infarction. Biomed Rep 3: 743-748, 2015. https://doi.org/10.3892/br.2015.500 
ORMSTAD H, VERKERK R, AASS HC, AMTHOR KF, SANDVIK L: Inflammation-induced catabolism of tryptophan and tyrosine in acute ischemic stroke. J Mol Neurosci 51: 893-902, 2013. https://doi.org/10.1007/s12031-013-0097-2

PARRY-BILLINGS M, BAIGRIE RJ, LAMONT PM, MORRIS PJ, NEWSHOLME EA: Effects of major and minor surgery on plasma glutamine and cytokine levels. Arch Surg 127: 1237-1240, 1992. https://doi.org/10.1001/archsurg.1992.01420100099017

PUCHALSKA P, CRAWFORD PA: Multi-dimensional roles of ketone bodies in fuel metabolism, signaling, and therapeutics. Cell Metab 25: 262-284, 2017. https://doi.org/10.1016/j.cmet.2016.12.022

REHNCRONA S, ROSÉN I, SIESJÖ BK: Brain lactic acidosis and ischemic cell damage: 1. Biochemistry and neurophysiology. J Cereb Blood Flow Metab 1: 297-311, 1981. https://doi.org/10.1038/jcbfm.1981.34

REHULKOVA H, REHULKA P, MYSLIVCOVA FUCIKOVA A, STULIK J, PUDIL R: Identification of novel biomarker candidates for hypertrophic cardiomyopathy and other cardiovascular diseases leading to heart failure. Physiol Res 65: 751-762, 2016. https://doi.org/10.33549/physiolres.933253

RODRÍGUEZ-PÉREZ R, FERNÁNDEZ L, MARCO S: Overoptimism in cross-validation when using partial least squares-discriminant analysis for omics data: a systematic study. Anal Bioanal Chem 410: 5981-5992, 2018. https://doi.org/10.1007/s00216-018-1217-1

RUAN HB, CRAWFORD PA: Ketone bodies as epigenetic modifiers. Curr Opin Clin Nutr Metab Care 21: 260-266, 2018. https://doi.org/10.1097/MCO.0000000000000475

SHAH SH, KRAUS WE, NEWGARD CB: Metabolomic profiling for the identification of novel biomarkers and mechanisms related to common cardiovascular diseases: form and function. Circulation 126: 1110-1120, 2012. https://doi.org/10.1161/circulationaha.111.060368

SHAH AM, WANG Z, MA J: Glutamine metabolism and its role in immunity, a comprehensive review. Animals (Basel) 10: pii: E326, 2020. https://doi.org/10.3390/ani10020326

SHIMAZU T, HIRSCHEY MD, NEWMAN J, HE W, SHIRAKAWA K, LE MOAN N, GRUETER CA, LIM H, SAUNDERS LR, STEVENS RD, NEWGARD CB, FARESE RV JR, DE CABO R, ULRICH S, AKASSOGLOU K, VERDIN E: Suppression of oxidative stress by beta-hydroxybutyrate, an endogenous histone deacetylase inhibitor. Science 339: 211-214, 2013. https://doi.org/10.1126/science.1227166

SIDOROV E, SANGHERA DK, VANAMALA JKP: Biomarker for ischemic stroke using metabolome: a clinician perspective. J Stroke 21: 31-41, 2019. https://doi.org/10.5853/jos.2018.03454

SU X, WELLEN KE, RABINOWITZ JD: Metabolic control of methylation and acetylation. Curr Opin Chem Biol 30 : 52-60, 2016. https://doi.org/10.1016/j.cbpa.2015.10.030

SMOLDEREN KG, SPERTUS JA, REID KJ, BUCHANAN DM, KRUMHOLZ HM, DENOLLET J, VACCARINO V, CHAN PS: Circ Cardiovasc Qual Outcomes 2: 328-337, 2009. https://doi.org/10.1161/circoutcomes.109.868588

SULEIMAN MS, MOFFATT AC, DIHMIS WC, CAPUTO M, HUTTER JA, ANGELINI GD, BRYAN AJ: Effect of ischaemia and reperfusion on the intracellular concentration of taurine and glutamine in the hearts of patients undergoing coronary artery surgery. Biochim Biophys Acta 1324: 223-231, 1997. https://doi.org/10.1016/s0005-2736(96)00225-8

TOURNISSAC M, VANDAL M, TREMBLAY C, BOURASSA P, VANCASSEL S, EMOND V, GANGLOFF A, CALON F: Dietary intake of branched-chain amino acids in a mouse model of Alzheimer's disease: Effects on survival, behavior, and neuropathology. Alzheimers Dement (N Y) 4: 677-687, eCollection 2018. https://doi.org/10.1016/j.trci.2018.10.005

TREBATICKÁ J, DUKÁT A, ĎURAČKOVÁ Z, MUCHOVÁ J: Cardiovascular Diseases, depression disorders and potential effects of omega-3 fatty acids. Physiol Res 66: 363-382, 2017. https://doi.org/10.33549/physiolres.933430

USSHER JR, ELMARIAH S, GERSZTEN RE, DYCK JR: The emerging role of metabolomics in the diagnosis and prognosis of cardiovascular disease. J Am Coll Cardiol 68: 2850-2870, 2016. https://doi.org/10.1016/j.jacc.2016.09.972

XIA J, BROADHURST DI, WILSON M, WISHART DS: Translational biomarker discovery in clinical metabolomics: an introductory tutorial. Metabolomics 9: 280-299, 2013. https://doi.org/10.1007/s11306-012-0482-9 
ZHANG Z, XU X: Lactate clearance is a useful biomarker for the prediction of all-cause mortality in critically ill patients: a systematic review and meta-analysis*. Crit Care Med 42: 2118-2125, 2014. https://doi.org/10.1097/ccm.0000000000000405 